Journal American Society of Mining and Reclamation, 2017 Vol.6, No.1

\title{
USE OF CAMERA TRAPPING TO DETERMINE SPATIAL DISTRIBUTION, HABITAT USE, AND ENVIRONMENTAL FACTORS AFFECTING MESOPREDATORS ON RECLAIMED MINE LANDS AT THE WILDS ${ }^{1}$
}

\author{
Katherine Driscoll ${ }^{2}$, Matt Lacey, and Joe Greathouse
}

\begin{abstract}
There have been few studies conducted on mammalian mesopredators on reclaimed mine sites. The Wilds, a 9,154-acre conservation center located in Eastern Ohio, was surface mined for coal from the 1940s-1980s and reclamation began in 1971 (History, 2015). Coyotes (Canis latrans) and bobcats (Lynx rufus) are the main mesopredators located at the Wilds and were the primary focus of this study. Camera trapping was used to assess how ecological factors impacted the habitat use and distribution of bobcats and coyotes on reclaimed mine land. Ten remote cameras were randomly deployed across the property to monitor the biological community at the Wilds from late January to early July. Statistical analyses were used to determine the impact of variable conditions on the number of bobcat and coyote observations at all camera traps. These conditions included the seasons, time period, baiting, edge versus interior habitat, mining effects, snow cover, and the level of human activity. It was determined that coyotes did not closely associate with any habitat types, while they did closely associate with several scavenging species. Bobcats were most closely associated with large prey items, such as the white-tailed deer, wild turkey, and eastern cottontail and were also closely associated with open or sparsely covered habitats. The results of Pearson's chi-squared tests determined that photographs of bobcats during this study were captured significantly more often when the camera trap was located on an unmined site, when the trap was baited, when snow cover was present, during nocturnal periods, and during winter. This study reaffirmed the ability of remote camera traps to effectively survey elusive species that may occur at low densities such as the bobcat and the coyote. The data collected from this study has demonstrated that although the effects of mining were extensive at the Wilds, the mesopredator populations of bobcats and coyotes have returned to this recovering landscape.
\end{abstract}

${ }^{1}$ Paper submitted to JASMR for consideration from work done at the Wilds.

${ }^{2}$ Katherine Driscoll is Wildlife Ecology Apprentice, the Wilds, Cumberland, $\mathrm{OH}$ 43732; Matt Lacey is Wildlife Ecology Intern, the Wilds, Cumberland, OH 43732. Dr. Joe Greathouse is Assistant Professor of Biology, West Liberty University, West Liberty, WV 26074

DOI: http://doi.org/10.21000/JASMR17010015 


\section{Introduction}

Monitoring wildlife populations is an essential component of wildlife management and conservation. Camera trapping is a non-invasive research technique that allows for the monitoring and detection of wildlife, particularly elusive species, without the need for additional methods such as physical capture or marking that may jeopardize the safety of the animal and the handler. The ability to monitor species that are cryptic and occur at low densities can be extremely difficult, but camera traps have been successfully used to document images and estimate density for multiple species (Heilbrun et al., 2006; Kelly and Holub, 2008). The utilization of camera traps can also record and monitor a variety of environmental factors that may be associated with the observations of a target species. Some of these factors include determining the prey communities present within an area, the relationship between the presence of two predator species, habitat selection, movement of a target species during different seasons, and the movement during each day.

Bobcats (Lynx rufus) are carnivores that occur in southern Canada, across the United States, and most of Mexico (Larivière and Watson, 1997). The bobcat exhibits the largest range of all cats native to North America (Whitaker, 1996). Bobcats are typically solitary hunters which actively search their home ranges for prey. Bobcat movement rates peak during the crepuscular time period, with the highest movements occurring at dusk (Rockhill et al., 2013). The main prey of bobcats in eastern Ohio are eastern cottontails (Sylvilagus floridanus) and white-tailed deer (Odocoileus virginianus) (Prange and Rose, 2015). Due to the lack of documented sightings, the bobcat was considered extirpated from Ohio in 1850. The initial decrease in sightings was associated with the expansion of the human population within the state and increased activity from industry, but populations have slowly been increasing. Bobcats were listed as endangered on the Ohio Department of Natural Resources State Listed Species Index in 1974. In 2012, bobcats were downlisted to threatened, and by 2014 the species was delisted (Ohio Division of Wildlife, 2014).

Unlike the native bobcat, coyotes are recent additions to the mammalian community of the eastern United States. Originally only occurring in the west, their rapid colonization in Ohio began around 90 years ago (Kays et al., 2009). As colonial America expanded westward, native predators were extirpated or populations declined, and the opportunistic coyote began to expand its range. The earliest coyote sighting in Ohio was in 1919, and the first documented coyote observed in Muskingum County, the site of our study, was in 1949 (Weeks et al., 1990). As these mid-sized 
canids moved eastward, it is believed that they may have hybridized with wolves in the Great Lakes region; however, there is little evidence to support the hybridization of coyotes in Ohio (Bozarth et al., 2011). Coyotes have succeeded in filling the void left by former top predators such as the gray wolf (Canis lupus) and the eastern cougar (Puma concolor), and in some areas the American black bear (Ursus americanus) (Mech, 1970). The opportunistic nature of the coyote has allowed them to thrive in the now mostly predator-free eastern United States.

The feeding habits of coyotes are well documented and may vary notably across their broad range and change seasonally. Most studies indicate that coyotes primarily rely upon white-tailed deer (Odocoileus virginianus) and the eastern cottontail rabbit (Sylvilagus floridanus), with some seasonal fluctuation between their primary prey species (Korschgen, 1957; Patterson et al., 1998; Crimmins et al., 2012). In the early summer, white-tailed deer fawns comprise a large portion of their diet (Patterson et al., 1998). However, coyotes are omnivorous, sometimes feeding on berries and vegetation. When available, blueberries (Vaccinium spp.) and raspberries (Rubus spp.) are known to be important food items (Harrison and Harrison, 1984). It is well documented that coyotes have preyed upon domesticated poultry such as chickens and turkey; however, they are generally minimally economically destructive and detrimental to domestic animals (Korschgen, 1957). Also, past studies show that injured or older animals are the most destructive to agricultural interests, thus depredation is not a common occurrence (Korschgen, 1957).

Some coyotes live in social groups, while others may remain solitary. Solitary coyotes will change their territory frequently and cover large areas in a short period of time. Social group, or pack, formation likely evolved as an adaptation to allow for more efficient prey capture (Messier and Barrette, 1981). Usually packs are centered on a breeding pair that may include some nonbreeding offspring that may assist in pup rearing and defending food supplies. The breeding pair forms a monogamous pair bond and will mate annually between January and April. Females have a nine-week gestation period and produce litters with an average of 6 pups. Pups will remain in the den - typically a hole dug in the ground - for at least 3 months, and may disperse when they're between 6 and 9 months of age. Pups may remain solitary until they locate a mate or an unoccupied territory. Social structure is variable and difficult to predict, and is likely related to prey size, distribution, and availability (Bekoff and Wells, 1980). 
Habitat selection and activity patterns of coyotes may be variable. Past studies indicate that home ranges can vary in size from $4.1 \mathrm{~km}^{2}$ to $68.7 \mathrm{~km}^{2}$. It was once believed that coyotes only inhabited prairie or brush edge habitat bordering timber or farmlands (Korschgen, 1957). It is well documented that they will inhabit forested areas, or in some cases in habitat clear-cuts--defined as timber harvest within 10 years (Crimmins et al., 2012). Ordeñana (2010) reported an increase in occurrence of coyotes in areas with reduced proximity to and increased intensity of urbanization. Coyotes are more active during crepuscular and nocturnal periods, and individuals inhabiting areas of high human disturbance may compensate for reduced diurnal activity with more nocturnal activity (McClennen et al., 2001).

Today, coyotes occur in the majority of the continental United States, Alaska, Canada, Mexico, and Central America. Due to their large range, their conservation status is a species of least concern (Gese, 2008). Although there have been extensive studies on reptiles, amphibians, and other mammal species, there are few studies on mammalian mesopredators at active or reclaimed mine sites (Buehler and Percy, 2012). While information on their diet, distribution, habitat selection, and activity patterns are well documented, these behaviors have not been assessed in eastern Ohio. Due to their large geographic range, bobcats have become a well-studied species. Although there are numerous published accounts of bobcat spatial distribution, habitat selection and diet (Boyle and Fendley, 1987; Chamberlain et al. 2003; Larivière and Watson, 1997; Litvaitis et al. 1986; Nielsen and Woolf, 2001; Prange and Rose, 2015), the effects of past industrial or mining activities have not been extensively studied. From the 1940s to the 1980s, approximately $56.7 \%$ of the Wilds property was surface-mined for coal. There were 11 verified sightings of bobcats within Muskingum county in 1970 as opposed to 50 that were documented in 2013 (Ohio Division of Wildlife, 2014).

The objectives of this study were to estimate and quantify the significance of ecological factors on the distribution and habitat use of the current bobcat and coyote populations on the reclaimed mine lands of the Wilds' property. Ecological factors that were analyzed during this study included the habitat selection and use across the diel period and seasons; the correlation of bobcat and coyote presence to an increasing distance from roads or edge habitats and mined or unmined habitats; and the association of bobcats and coyotes' presence with each other, within their habitats, prey species, with snow cover, and with baited traps. 
Journal American Society of Mining and Reclamation, 2017 Vol.6, No.1

\section{Methods}

Study Area

This study area comprised a total of 9,154 acres of the Wilds, a private non-profit conservation center located on reclaimed mine lands in Muskingum County, Ohio. Average annual precipitation totaled 961 millimeters $(\mathrm{mm})$. Average temperatures ranged from $5.2^{\circ} \mathrm{C}$ in winter, $19.4^{\circ} \mathrm{C}$ in spring, to $27.1^{\circ} \mathrm{C}$ in summer (U.S. Climate Data, 2015). The average elevation of the total area of Wilds property is 314.6 meters $(\mathrm{m})$. The primary land use at the Wilds consisted of deciduous forest $(47.14 \%)$, grassland/herbaceous cover (39.61\%), open water in the form of lakes and ponds (4.70\%), and pasture/hay managed land (3.99\%), as described by the National Land Cover Database Legend Land Cover Class Descriptions (Homer et al., 2015).

\section{$\underline{\text { Data Collection }}$}

Camera trapping locations were selected by dividing the total area of Wilds property into ten equal sections by area using Google ${ }^{\mathrm{TM}}$ Earth (see Table 1 and Fig. 1). Each of the ten sections of property were then separated into 100 square meter $\left(\mathrm{m}^{2}\right)$ cells and one set of GPS coordinates was randomly selected per section of property with replacement using Program R (R Core Team, 2013). One of the camera traps was positioned and actively recording data before this project began and those GPS coordinates were utilized as the camera trap position in that area of the property. This camera was also baited with a road kill white-tailed deer before the project began. The camera was continually re-baited from February 2015 to April 2015 in order to determine the effects of bait to bobcat and coyote presence or absence at our camera trap locations. One camera was attached to a tree trunk or thick fence post at each set of GPS coordinate sites. Camera placement was chosen based on the type of habitat, such as evergreen or deciduous forest; habitat features, such as hollow logs or rocky outcroppings; and whether the area was an edge or interior habitat (Boyle and Fendley, 1987). Once the camera was placed on a tree, the location was marked on the GPS unit and the GPS coordinates were recorded.

Camera surveys were completed weekly from February 2015 through July 2015. Cameras remained active for 24 hours a day and photographs were collected once per week, except in extreme weather conditions. In extreme weather conditions, photos were collected during the following week. Bushnell ${ }^{\odot}$ Trophy Cams were used, which are digital camera traps that were triggered to take high resolution pictures whenever an animal broke a highly sensitive Passive Infra-Red (PIR) motion sensor. All camera traps were set to capture 2 photographs per trigger at 
a 1 minute interval until it responds to any additional triggers from the infra-red motion sensor. Each photograph was set to have a resolution of 6 megapixels to ensure the best quality photos available. The sensor level was set to "Auto" which allows the camera to determine the best setting based on its current operating temperature. The time stamp was activated in all of the camera traps in order to have all photographs imprinted with the date and time of capture (Bushnell ${ }^{\odot}$ Outdoor Products, 2014). Cameras were mounted approximately $25-50 \mathrm{~cm}$ above the ground, ensuring that an animal as small as a bobcat or raccoon, as well as white-tailed deer would trigger the motion sensor. When necessary, understory growth was cleared in order to minimize false triggering and to allow the production of unobstructed photographs.

Table 1. Coordinate Locations of Camera Traps.

\begin{tabular}{|c|c|c|}
\hline Camera Trap & Longitude & Latitude \\
\hline 1 & -81.73890 & 39.90030 \\
\hline 2 & -81.74084 & 39.89594 \\
\hline 3 & -81.75205 & 39.88863 \\
\hline 4 & -81.72242 & 39.87929 \\
\hline 5 & -81.72128 & 39.86640 \\
\hline 6 & -81.74464 & 39.86138 \\
\hline 7 & -81.71224 & 39.84319 \\
\hline 8 & -81.69466 & 39.83797 \\
\hline 9 & -81.74663 & 39.82251 \\
\hline 10 & -81.71962 & 39.81458 \\
\hline
\end{tabular}

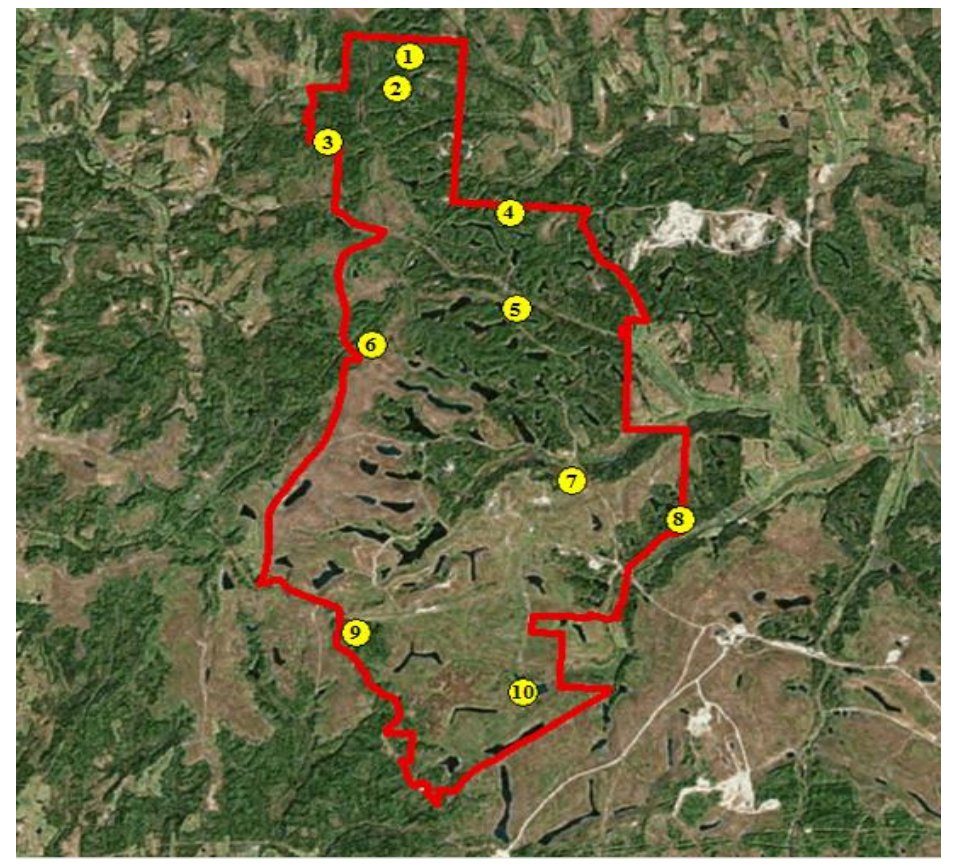

Figure 1. Map of Wilds property with locations of 10 camera traps. 
Journal American Society of Mining and Reclamation, 2017 Vol.6, No.1

\section{$\underline{\text { Data Analysis }}$}

The total trap nights were based on the summary of the total number of days that the camera traps were recording and then subtracting the days where cameras malfunctioned. The number of species occurrences was calculated by counting the number of individuals of a species that passed in front of each camera trap. A new individual occurrence was documented when an animal entered the view approximately 5 minutes after the previous individual left the view screen. The number of occurrences per species was used to represent the biological communities at each camera trap location. The date and time recorded on each photograph, as well as the position and individual tracks of the animal, assisted in separating species occurrences and to eliminate double counting. Chi-square tests were used to determine whether environmental or landscape variables differed between the number of observations of bobcats and coyotes photographed. Habitat conditions included the seasons, time period, baiting, edge versus interior habitat, mining effects, and the presence of snow cover. The time period was defined as diurnal (sunrise to sunset) and nocturnal (sunset to sunrise). The seasons were defined as winter (December 21st to March 19th), spring (March 20th to June 20th) and summer (June 21st to September 22nd). Data was not collected during the fall season because the researchers had completed their apprenticeship at the Wilds during the summer of 2015. To further analyze factors that may influence the presence of bobcats and coyote presence, Wilcoxon rank sums tests were used to determine the effect of continuous habitat variables associated with land use as well as the effect of the distance from the nearest maintained road and the distance from a hydraulic fracturing drill site being developed to the southwest of the Wilds property on the presence of bobcats or coyotes at trap sites.

A circular $3150.4 \mathrm{~m}$ buffer based on the average home range for a bobcat, was created surrounding each of the 10 camera trap sites (Nielsen and Woolf, 2001). Similarly, a circular buffer of 4,153.3 $\mathrm{m}$, the average home range for a coyote, was created surrounding each camera trap site (Crimmins et al., 2012). For each buffer, the percent land cover was extracted from the 2011 National Land Cover Dataset (NLCD). The distance of each camera trap location was calculated to the nearest maintained road and to the hydraulic fracturing site being developed to the southwest of the Wilds property with the line measurement tool in Google ${ }^{\mathrm{TM}}$ Earth. A BrayCurtis dissimilarity index was used to develop a non-metric multidimensional scaling (NMDS) model for analyzing the bobcat and coyote data. NMDS was utilized to examine the associations 
Journal American Society of Mining and Reclamation, 2017 Vol.6, No.1

between the presence of bobcats and coyotes and the type of habitat and the biological communities at the camera trap locations.

\section{Results}

From February 2015 to July 2015, a total of 1,391 nights was recorded but of these the cameras malfunctioned 44 times. After subtracting those days when cameras malfunctioned, the total number of trap nights was 1,314 (Table 2). Of the 2,732 trap events, the two prevalent species observed were the white-tailed deer (Odocoileus virginianus) and turkey vulture (Cathartes aura). The other common species in order of occurrence included the eastern gray squirrel (Sciurus carolinensis), raccoon (Procyon lotor), and eastern cottontail (Sylvilagus floridanus) (Fig. 6). Bobcats were photographed at 7 out of the 10 camera traps, which accounted for $0.86 \%$ of the total species occurrences. Photographs of bobcat and coyote trap events can be viewed in Fig. 2,3,4, and 5. Coyotes accounted for $2.95 \%$ of the captured photographs, which was a total of 79 trap events, and occurred at 8 of the 10 camera traps (Table 2 and Fig. 6).

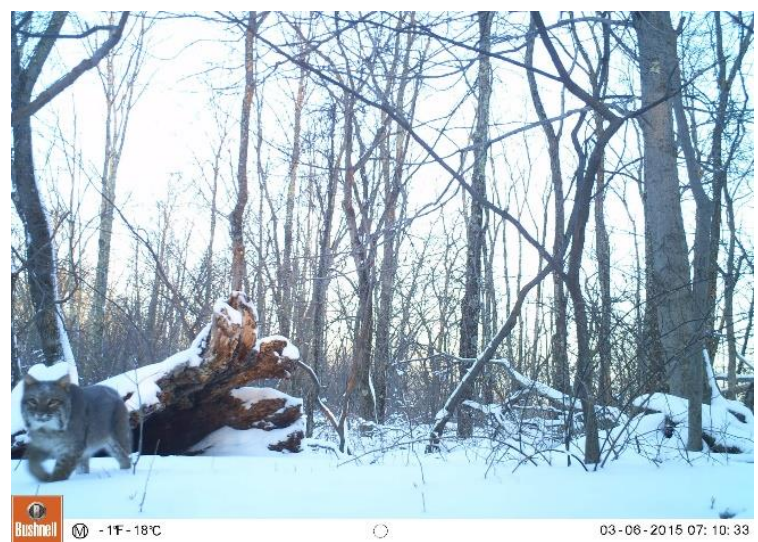

Figure 2. Bobcat emerging from hollow log.

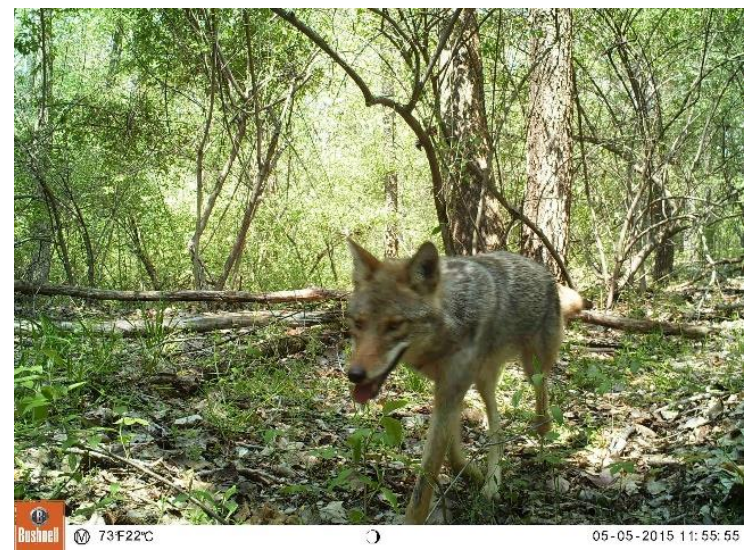

Figure 4. Coyote trotting past a camera.

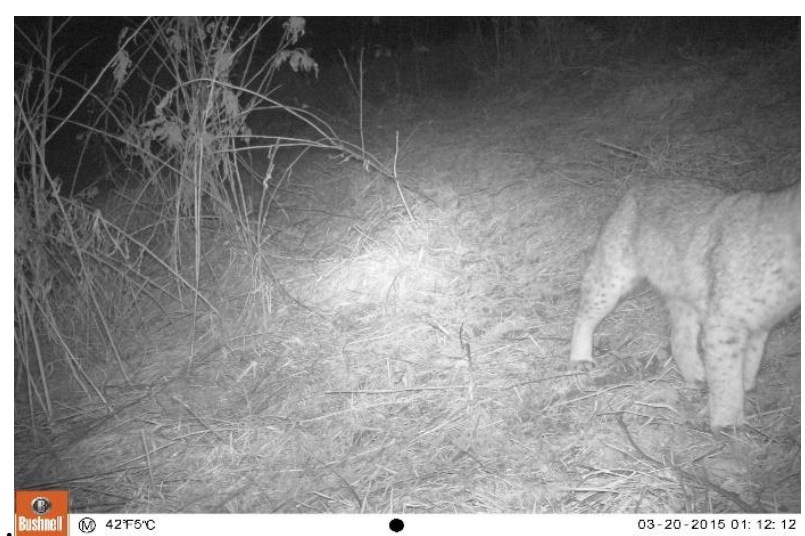

Figure 3. Bobcat on edge of lake at night.

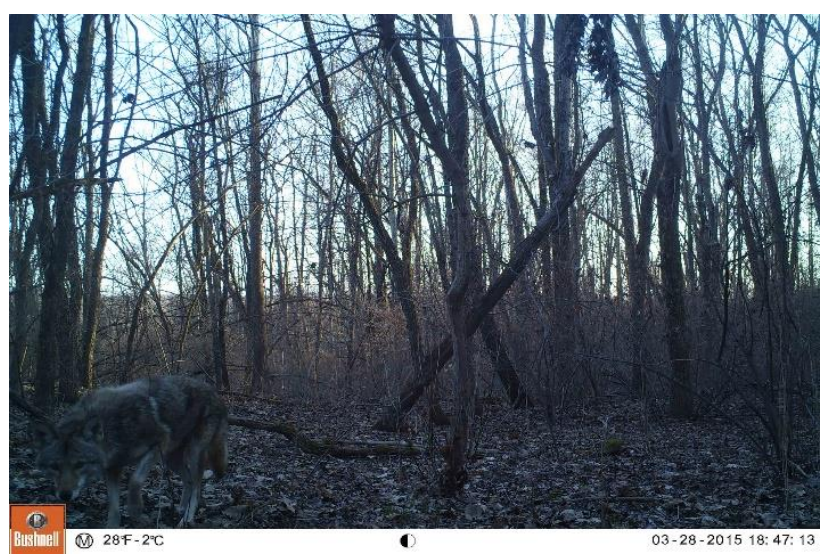

Figure 5. Coyote cautiously approaches camera. 
Table 2. Trap events and percentage of species occurrence for all camera locations from February 2015 to July 2015.

\begin{tabular}{ll} 
Total Number & $\begin{array}{c}\text { Tocies (Common Name) } \\
\text { of Trap Events Percent of Occurrence }\end{array}$ \\
\hline \hline
\end{tabular}

\section{Mammals}

\begin{tabular}{lcc}
\hline White-Tailed Deer & 769 & $28.75 \%$ \\
Eastern Gray Squirrel & 463 & $17.31 \%$ \\
Raccoon & 267 & $9.98 \%$ \\
Eastern Cottontail Rabbit & 105 & $3.93 \%$ \\
Coyote & 79 & $2.95 \%$ \\
Virginia Oppossum & 60 & $2.24 \%$ \\
Fox Squirrel & 47 & $1.76 \%$ \\
Bobcat & 23 & $0.86 \%$ \\
Jumping Mouse & 11 & $0.41 \%$ \\
Eastern Chipmunk & 11 & $0.42 \%$ \\
Striped Skunk & 6 & $0.23 \%$ \\
Dog & 4 & $0.15 \%$ \\
Long-Tailed Weasel & 3 & $0.11 \%$ \\
Beaver & 3 & $0.11 \%$ \\
Southern Flying Squirrel & 2 & $0.07 \%$ \\
Red Fox & 1 & $0.04 \%$ \\
Mink & 1 & $0.04 \%$ \\
Gray Fox & 1 & $0.04 \%$ \\
Cat & 1 & $0.04 \%$
\end{tabular}

\section{$\underline{\text { Birds }}$}

Turkey Vulture $\quad 543 \quad 20.30 \%$

Wild Turkey $\quad 56 \quad 2.09 \%$

American Robin $\quad 54 \quad 2.02 \%$

Wood Thrush $\quad 39 \quad 1.46 \%$

American Crow $\quad 33 \quad 1.23 \%$

Red-Tailed Hawk $\quad 31 \quad 1.16 \%$

Bluejay $12 \quad 0.45 \%$

Eastern Screech Owl $\quad 9 \quad 0.34 \%$

Peromyscus Mouse $\quad 7 \quad 0.26 \%$

$\begin{array}{lll}\text { Red-Bellied Woodpecker } & 6 & 0.22 \%\end{array}$

Canada Geese $\quad 5 \quad 0.19 \%$

Northern Cardinal $\quad 4 \quad 0.15 \%$

House Sparrow $30.11 \%$

Song Sparrow $\quad 3 \quad 0.11 \%$

Downy Woodpecker $\quad 2 \quad 0.07 \%$

$\begin{array}{lll}\text { Rufous-Sided Towhee } & 2 & 0.07 \%\end{array}$

Northern Flicker Woodpecker $\quad 2 \quad 0.07 \%$

Brown Thrasher $\quad 1 \quad 0.04 \%$

Dark-Eyed Junco $\quad 1 \quad 0.04 \%$

Ovenbird $\quad 1 \quad 0.04 \%$

Pileated Woodpecker $\quad 1 \quad 0.04 \%$

$\begin{array}{lll}\text { Tufted Titmouse } & 1 & 0.04 \%\end{array}$

Red-winged Blackbird $\quad 1 \quad 0.04 \%$

Gray Catbird $\quad 1 \quad 0.04 \%$

Total Sum of Trap Events 2675

Total Number of Trap Nights 


\section{Species Occurrences}

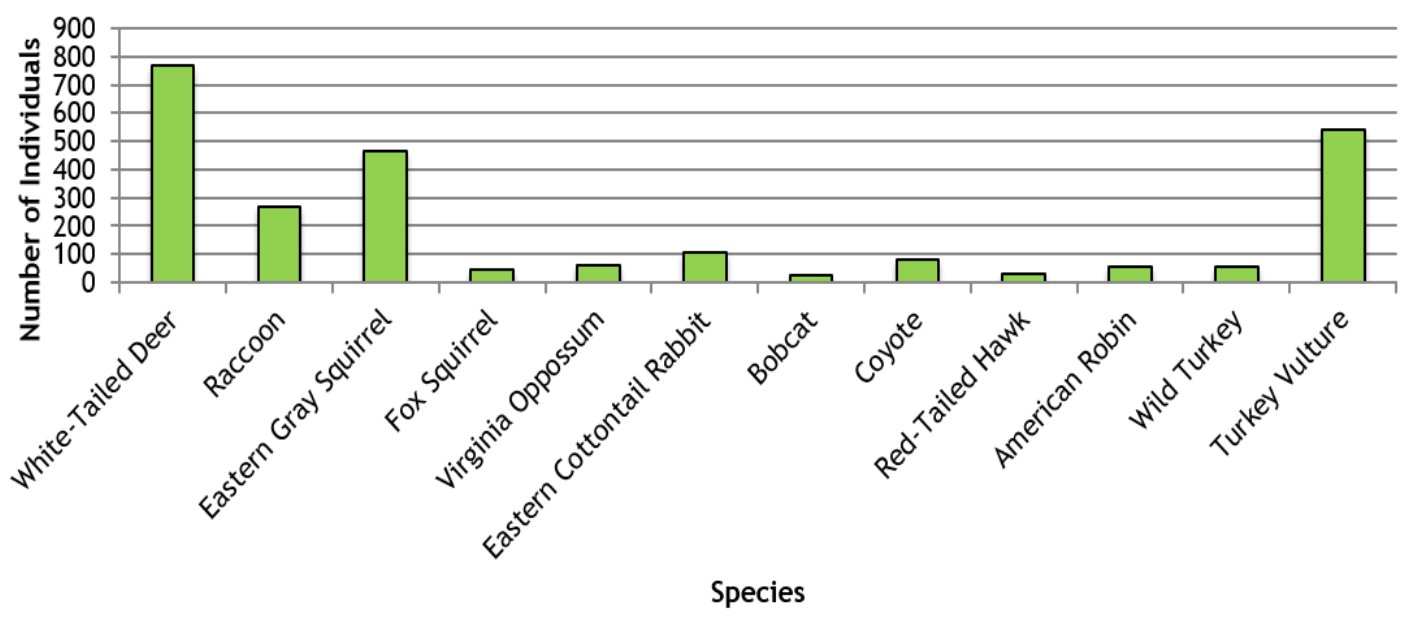

Figure 6. Number of individual trap events of species with a percent occurrence greater than $2 \%$.

The calculations of the Pearson's chi-squared tests revealed that bobcats were captured on cameras significantly more often during a variety of conditions including on an unmined site, if the trap was baited, and if the ground was snow covered. Bobcats were captured on cameras more often at night and during the winter than during other seasons of the year (Table 3). There was not a significant relationship between the bobcats captured on cameras located at an edge habitat or an interior habitat.

Based on a Non-Metric Multidimensional Scaling (NMDS), bobcat occurrences were more closely associated with the biological communities of white-tailed deer (Odocoileus virginianus), wild turkey (Meleagris gallopavo), and eastern cottontail (Sylvilagus floridanus) (Fig. 7). The occurrence of bobcats was more often associated with open water, developed open space, grassland/herbaceous, and shrub/scrub habitats on the Wilds property. Bobcats were captured more often on cameras located at sites 3 and 10, whereas bobcats were not observed at sites 1, 9, and 5 (Fig. 8).

In contrast to bobcats, the results of the Pearson's chi-squared tests showed that coyotes were captured on cameras significantly more often in edge habitat and when there was no snow cover (Table 4). There was also a significant relationship between the occurrence of coyotes and habitat types (Table 5). Coyotes were more prevalent with increasing concentrations of deciduous forest and pasture/hay habitat types (Table 6). 


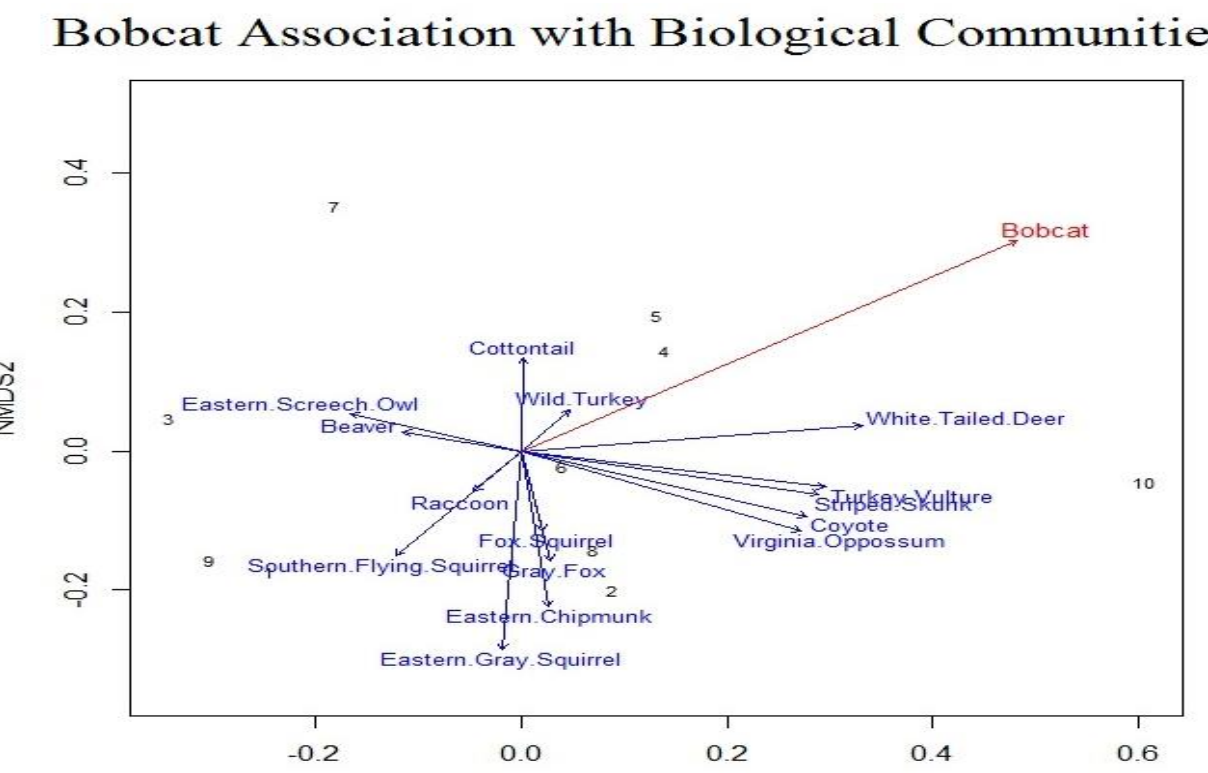

Figure 7. Non-metric multi-dimensional scaling (NMDS) analysis of the association of observed bobcats with observed biological communities. The numbers 1-10 represent one of the 10 camera trap locations.

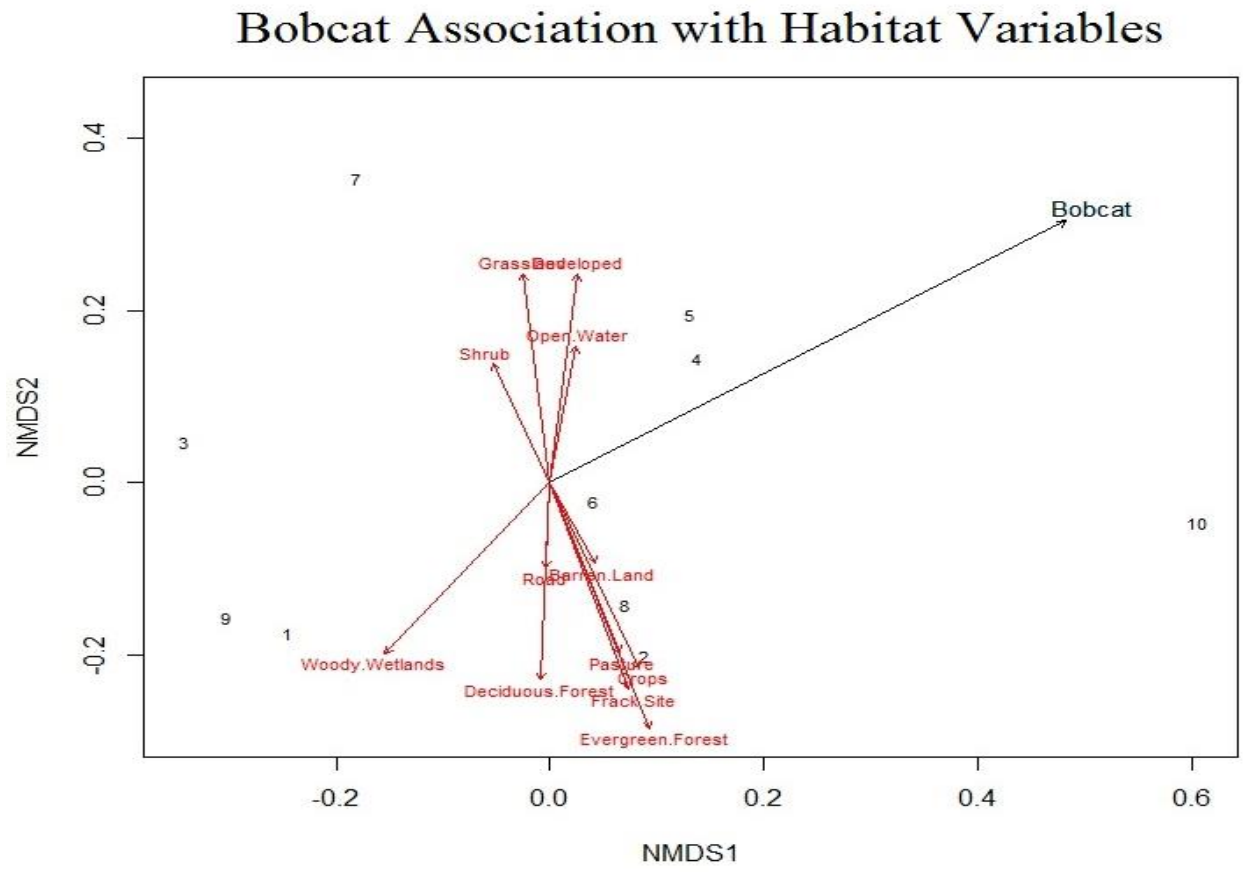

Figure 8. Non-metric multi-dimensional scaling (NMDS) analysis of the association of observed bobcats with extracted habitat variables. The numbers 1-10 represent one of the 10 camera trap locations. 
Journal American Society of Mining and Reclamation, 2017 Vol.6, No.1

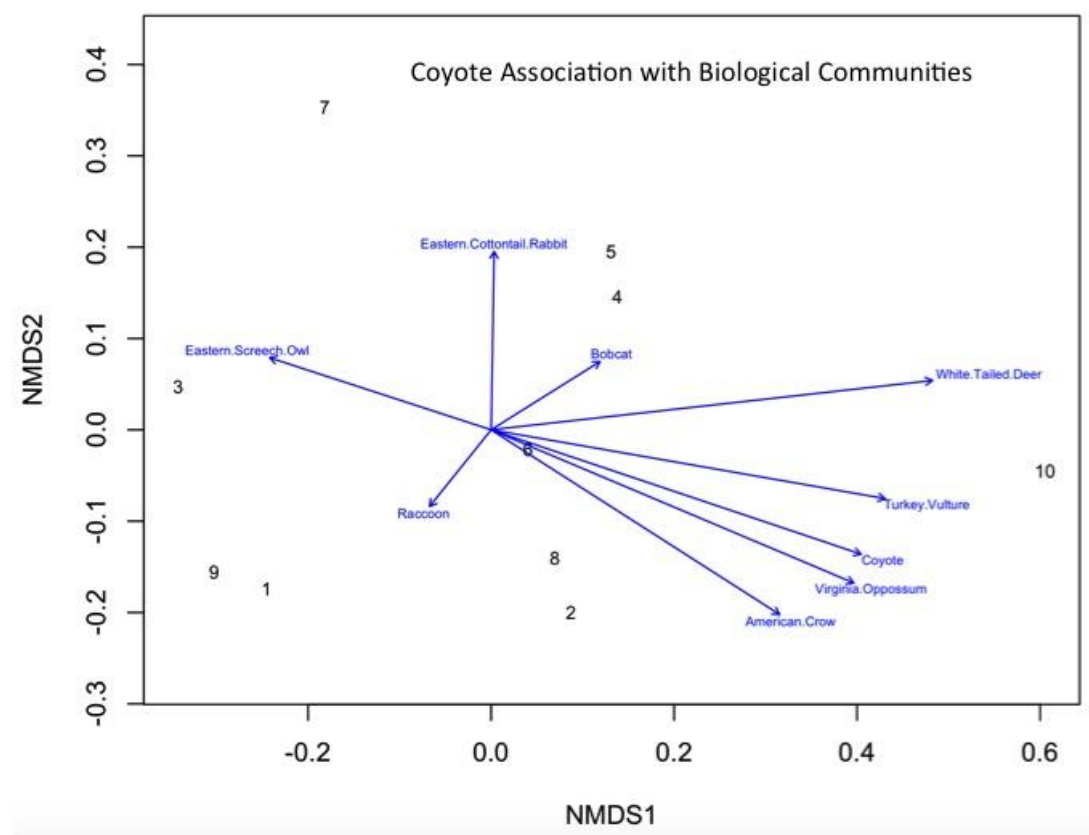

Figure 9. NMDS biplot of coyote associations with the biological community. The numbers 1-10 represent one of the 10 camera trap locations.

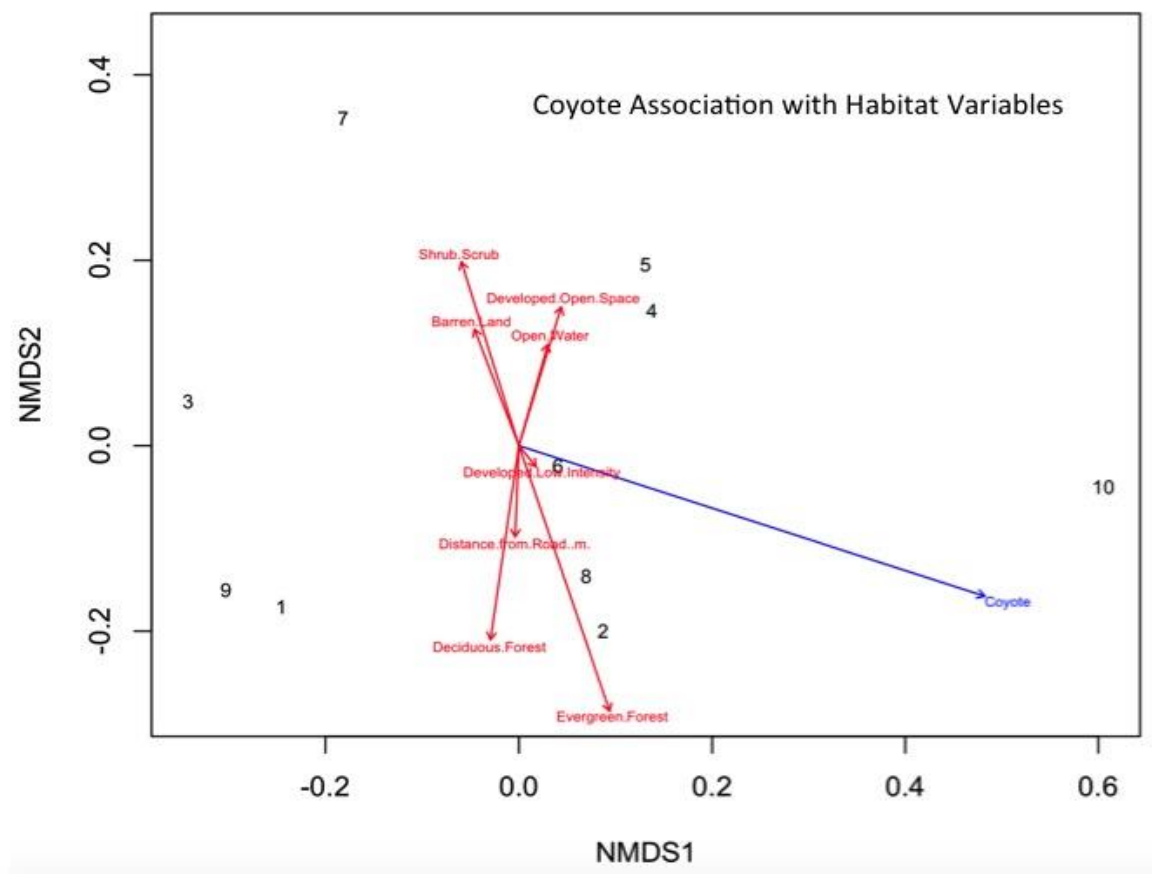

Figure 10. NMDS biplot of coyote associations with habitat variables. The numbers 1-10 represent one of the 10 camera trap locations. 
Table 3. Chi-squared calculation of the relationship between bobcat observations and variable conditions.

\begin{tabular}{lccc} 
Conditions & Chi-Squared Value & Calculated p-value & Preference \\
\hline Baited vs. Unbaited Trap & 6.8599 & 0.008815 & Baited \\
Snow vs. No Snow at Trap & 11.284 & 0.000782 & Snow \\
Seasons (Winter, Spring, Summer) & 14.993 & 0.000555 & Winter \\
Mined vs. Unmind Trap Location & 5.7786 & 0.01622 & Unmined \\
Nocturnal vs. Diurnal & 6.3161 & 0.01196 & Nocturnal \\
Edge vs. Interior Habitat & 2.1604 & $0.1416^{\dagger}$ & N/A \\
\hline
\end{tabular}

†Values are not significantly different at $p=0.05$ level.

Table 4. Chi-square test results, chi-squared value, p-value, and habitat preference.

\begin{tabular}{lccc} 
Conditions & Chi-squared value & P-value & Preference \\
\hline Edge vs. interior habitat & 20.487 & $6.004 \times 10^{-6}$ & Edge habitat \\
Snow vs. no snow & 50.332 & $1.298 \times 10^{-12}$ & No snow \\
Mined vs. not mined & 3.3626 & $0.06669^{\dagger}$ & N/A \\
Seasons (winter, spring, summer) & 2.8151 & $0.2447^{\dagger}$ & N/A \\
Diurnal vs. nocturnal & 0.34353 & $0.5578^{\dagger}$ & N/A \\
\hline
\end{tabular}

$\dagger$ Values aren't significantly different at $\mathrm{p}>0.05$.

Table 5. Wilcoxon rank sum tests results, habitat type, and p-value.

\begin{tabular}{lccc} 
Habitat Type & P-value & Mean Coyote Presence & Mean Coyote Absence \\
\hline Deciduous Forest & 0.04949 & 57.375 & 35 \\
Pasture/Hay & 0.04949 & 12.75 & 1.5 \\
\hline
\end{tabular}

tValues are not significantly different at $p=0.05$ level.

According to a Non-Metric Multidimensional Scaling (NMDS), within the biological communities at the Wilds, coyotes were more often associated with sites where turkey vultures, Virginia opossum (Didelphis virginiana), and the American crow (Corvus branchyrhynchos) were also captured on cameras (Fig. 9). Coyotes were not closely associated with any particular habitat type (Fig. 10).

\section{Discussion}

Bobcats were photographed at 7 out of the 10 camera traps, which accounted for $0.86 \%$ of the total species occurrences. Coyotes accounted for $2.95 \%$ of the captured photographs, which was a total of 79 trap events, and were found at 8 of the 10 camera traps. Bobcats and coyotes were observed during every month of the study from January to June. Both solitary and paired coyotes were photographed. These data suggest that the resident coyote population was widely distributed 
throughout the study area. Individual and pairs of coyotes were captured on cameras every month in all regions of the study area, whereas bobcats were only observed as single individuals suggesting that bobcats are typically solitary hunters (Rockhill et al., 2013; Larrucea et al., 2007; Larivière and Watson, 1997). The data collected in this study also confirmed that the reclaimed mine lands at the Wilds supported a diverse biological community, with at least 18 mammalian species and 23 avian species captured by the camera traps. White-tailed deer was the most frequently photographed species, which is encouraging because this is the primary prey species for the coyote (Korschgen, 1957; Patterson et al., 1998; Crimmins, 2012), as well as a prey species of the bobcat (Prange and Rose, 2015). Turkey vulture, eastern gray squirrel and raccoon were among the species with highest frequency of occurrence of being captured on the camera traps. Other predatory mammalian species captured on the camera traps included long-tailed weasel (Mustela frenata), American mink (Neovison vison), red fox (Vulpes vulpes), and gray fox (Urocyon cinereoargenteus), indicating the diversity of the prey community at the Wilds.

There was not a seasonal variation in the number of coyotes captured on cameras (winter, spring, or summer), or when the camera traps were baited with deer carcasses or between mine and nonmined lands. However, bobcats captured on camera increased and occurred more significantly (Pearson's chi-squared test, $\mathrm{p}$-value $=0.008815$ ) when the camera trap was baited. However, only one camera was baited on two separate occasions during the winter. For future studies, it would be advisable to bait more if not all the sites to increase the capture of both coyotes and bobcats at the camera traps. An additional trapping period in the fall season may also reveal a seasonal effect on coyote and bobcat camera trapping success, since more coyotes were captured on cameras when there was not snow on the ground. The three camera traps that were placed along forest edge captured significantly ( $\mathrm{p}$-value $=6.004 \times 10^{-6}$ ) more coyotes than the cameras in interior forest habitat. Korschgen (1957) believed that coyotes were found more often in prairie or brush land edge bordering timber rather than forest interior. However, one of the camera traps in the present study located in edge habitat was baited which may have influenced the results. Forest edge allows for easy and efficient movement, which is key for a species like the coyote which maintains a territory, and may be the reason that coyotes were photographed more often at the edge site cameras. Forest edges constitute areas of deciduous, evergreen, or mixed forests (that borders another habitat types.) This may also suggest that coyotes prefer these disturbed habitats rather than undisturbed habitats. 
In contrast to coyotes, bobcats were captured on cameras significantly more often ( $\mathrm{p}$-value= 0.000782 ) during the winter when snow cover was present at the camera location. The availability of bobcat prey may decrease during the winter season, requiring bobcats to increase their movements to secure prey within their defined home range boundaries (Chamberlain et al., 2003). Bobcats likely will hunt within the confines of their home range due to the limited mobility in deep snow, which may explain why significantly more bobcats were captured more often in the winter snow cover (Litvaitis et al., 1986). Bobcat photographs increased significantly ( $\mathrm{p}$-value $=0.01196$ ) during the nocturnal period which reflects the more nocturnal nature of the bobcat (Rockhill et al., 2013; Larrucea et al., 2007; Larivière and Watson, 1997). The seven unmined camera trap locations captured significantly more bobcat photographs ( $p$-value $=0.01622)$ than those on the three mined locations. Over 50 percent of the Wilds property was surface mined for coal, so it is possible that bobcats prefer the less disturbed areas of the property. The locations of camera traps at the forest edge or the forest interior did not show a significant difference on the capture rate of bobcats.

At the Wilds, coyotes were often captured in association with turkey vultures, Virginia opossums, and the American crow, which are considered to be scavenging species. These species did not associate as closely with bobcats, the other major mesopredator found on property, or with two of their main prey items, the white-tailed deer and the eastern cottontail rabbit. It is well documented that coyotes are omnivorous and opportunistic feeders. It is possible that in the past, the importance of scavenging has been underestimated in the feeding habits of coyotes (Patterson et al., 1998). Further study of their diet using techniques such as fecal analysis may lead to more conclusive evidence about their diet and feeding behaviors at the Wilds.

Based on the species captured on cameras located in different habitats at the Wilds, bobcats were associated with the white-tailed deer, wild turkey, and the eastern cottontail. All of which are the major prey species of the bobcats in Ohio (Prange and Rose, 2015).

A comparison of habitat variables suggested that coyotes did not exhibit a habitat preference. The results of the NMDS biplot indicated that coyotes were not closely associated with any particular habitat type at the Wilds, although results of the Wilcoxon ranks sums test indicated a significant relationship between the occurrence of coyotes and increasing pasture/hay lands and deciduous forest habitats. Pasture/hay lands are highly disturbed habitats, enabling efficient travel 
and capture of prey due to the lack of cover. Deciduous forests are one of the most pristine, undeveloped habitat types on the property. The results of this study indicate that a highly adaptive species, such as the coyote can inhabit most reclaimed habitats in regions with a viable food source.

The analysis of bobcat photographs revealed that their presence was closely associated with open water, developed open space, shrub/scrub, and grassland/herbaceous habitats. Previous research has determined that bobcats prefer dense understory cover or mixed forest cover in order to facilitate their stalk and ambush style of predation (Neale and Sacks, 2001; Litvaitis et al., 1986; Chamberlain et al., 2003; Major and Sherburne, 1987), but these studies do not explain the presence of bobcats in the open or sparse understory habitats that exist at the Wilds. The explanation of the significance of cover and habitat selection by bobcats most likely is the relation to the availability of prey. Bobcat prey is usually not abundant within forested cover types (Boyle and Fendley, 1987). Therefore, the habitat preferences of the bobcat population at the Wilds is because those are the preferred habitat types of both the eastern cottontail and white-tailed deer.

In summary, both coyotes and bobcats inhabited a range of habitat types on reclaimed surface mined lands, and both species were able to adapt to a variety of environmental conditions that existed at the Wilds. The results of this study indicated the potential importance of scavenging in the feeding habits of coyotes. The results of this study suggest that bobcats preferred habitats that were inhabited by their major prey species, especially the white-tailed deer and the eastern cottontail. Although extensive surface mining occurred at the Wilds, these two mesopredators were able to re-populate the area following mining.

\section{Acknowledgements}

Thank you to Dr. Joe Greathouse for supervising the Wildlife Ecology department at the Wilds and working closely with Matt and I to complete this project, the statistics, and the publication of this paper. We would like to thank Lauren Carmona and Jack Rabe for hiking to the camera trap locations in all weather conditions for the past 6 months to collect images, troubleshoot malfunctions, and replace cameras. Finally, our deepest gratitude goes to the Wilds administration and staff who allowed us to conduct this research on the Wilds property. This project was supported by a grant from the Hearst Foundation. 
Journal American Society of Mining and Reclamation, 2017 Vol.6, No.1

\section{References}

Bekoff, M. and M.C. Wells. 1980. The social ecology of coyotes. Scientific American. 242: 130148. https://doi.org/10.1038/scientificamerican0480-130

Boyle, K.A. and T.T. Fendley. 1987. Habitat Suitability Index Models: Bobcat. Biological Report. 82(10.147).

Bozarth, C.A., F. Hailer, L.L. Rockwood, C.W. Edwards, and J.E. Maldonado. 2011. Coyote colonization of northern Virginia and admixture with Great Lakes wolves. Journal of Mammalogy. 92: 1070-1080. https://doi.org/10.1644/10-MAMM-A-223.1

Buehler, D.A. and K. Percy. 2012. Coal Mining and Wildlife in the Eastern United States: A Literature Review, Ph.D. Dissertation, University of Tennessee. 29 p.

Bushnell Outdoor Products. 2014. The SETUP Menu-Parameters and Settings. In: Bushnell Trophy Cam Instruction Manual. p. 17-20.

Chamberlain, M.J., B.D. Leopold, and L.M. Conner. 2003. Space Use, Movements and Habitat Selection of Adult Bobcats (Lynx rufus) in Central Mississippi. The American Midland Naturalist. 149(2):395-405. https://doi.org/10.1674/0003-0031(2003)149[0395:SUMAHS|2.0.CO;2

Crimmins, S.M., J.W. Edwards, and J.M. Houben. 2012. Canis latrans (Coyote) Habitat Use and Feeding Habits in Central West Virginia. Northeastern Naturalist. 19:411-420. https://doi.org/10.1656/045.019.0304

Gese, E.M., M. Bekoff, W Andelt, L. Carbyn, and F. Knowlton,. 2008. Canis latrans. The IUCN Red List of Threatened Species. Version 2015.2. 〈www.iucnredlist.org〉. Downloaded on 14 July 2015.

Harrison, D.J. and J.A. Harrison. 1984. Foods of Adult Maine Coyotes and Their Known-Aged Pups. Journal of Wildlife Management. 48: 922-926. https://doi.org/10.2307/3801439

Heilbrun, R.D., N.J. Silvy, M.J. Peterson, and M.E. Tewes. 2006. Estimating Bobcat Abundance Using Automatically Triggered Cameras. Wildlife Society Bulletin. 34(1):69-73. https://doi.org/10.2193/0091-7648(2006)34[69:EBAUAT]2.0.CO;2

History. 2015. Columbus Zoo and Aquarium. Accessed on July 2, 2015 from https://thewilds.columbuszoo.org/home/about/about-the-wilds/history.

Homer, C.G., Dewitz, J.A., Yang, L., Jin, S., Danielson, P., Xian, G., Coulston, J., Herold, N.D., Wickham, J.D., and Megown, K. 2015. Completion of the 2011 National Land Cover 


\section{Database for the conterminous United States-Representing a decade of land cover change}

information. Photogrammetric Engineering and Remote Sensing. 81(5):345-354.

Kays, R., A. Curtis, and J.J. Kirchman. 2009. Rapid evolution of northeastern coyotes via hybridization with wolves. Biology Letters. 6: 89-93. https://doi.org/10.1098/rsbl.2009.0575

Kelly, M.J. and E. L. Holub. 2008. Camera Trapping of Carnivores: Trap Success Among Camera Types and Across Species, and Habitat Selection by Species, on Salt Pond Mountain, Giles County, Virginia. Northeastern Naturalist. 15(2): 249-262. https://doi.org/10.1656/10926194(2008)15[249:CTOCTS]2.0.CO;2

Korschgen, L.J. 1957. Food Habits of the Coyote in Missouri. Journal of Wildlife Management, 21: 424-435. https://doi.org/10.2307/3796675

Larivière, S. and L.R. Watson. 1997. Lynx rufus. Mammalian Species. 563:1-8. https://doi.org/10.2307/3504533

Larrucea, E.S., G. Serra, M.M. Jaeger, and R.H. Barrett. 2007. Censusing Bobcats Using Remote Cameras. Western North American Naturalist. 67(4):538-548. https://doi.org/10.3398/15270904(2007)67[538:CBURC]2.0.CO;2

Litvaitis, J.A., J.A. Sherburne, and J.A. Bissonette. 1986. Bobcat Habitat Use and Home Range Size in Relation to Prey Density. The Journal of Wildlife Management. 50(1):110-117. https://doi.org/10.2307/3801498

Major, J.T. and J.A. Sherburne. 1987. Interspecific Relationships of Coyotes, Bobcats, and Red Foxes in Western Maine. The Journal of Wildlife Management. 51(3):606-616. https://doi.org/10.2307/3801278

McClennen, N., R.R. Wigglesworth, S.H. Anderson, and D.G. Wachob. 2001. The Effect of Suburban and Agricultural Development on the Activity Patterns of Coyotes (Canis Latrans). American Midland Naturalist. 146: 27-36. https://doi.org/10.1674/00030031(2001)146[0027:TEOSAA]2.0.CO;2

Mech, L.D. 1970. The wolf: the ecology and behavior of an endangered species. Natural History Press, Garden City, New York. 384 p.

Messier, F. and C. Barrette. 1982. The social system of the coyote (Canis latrans) in a forested habitat. Canadian Journal of Zoology. 60: 1743-1753. https://doi.org/10.1139/z82-227

Neale, J.C.C. and B.N. Sacks. 2001. Resource Utilization and Interspecific Relations of Sympatric Bobcats and Coyotes. OIKOS. 94:236-249. https://doi.org/10.1034/j.1600$\underline{0706.2001 .940204 . x}$ 
Nielsen, C.K. and A. Woolf. 2001. Spatial Organization of Bobcats (Lynx rufus) in Southern Illinois. The American Midland Naturalist. 146(1): 43-52. https://doi.org/10.1674/00030031(2001)146[0043:SOOBLR]2.0.CO;2

Ohio Division of Wildlife. 2014. Summary of 2013 Bobcat Observations in Ohio. Waterloo Wildlife Research Station, Athens, $\mathrm{OH}$.

Ordeñana, M. 2005. The Effects of Urbanization on Carnivore Species Distribution and Richness in Southern California, Master of Science Thesis, University of Southern California. 28 p.

Patterson, B.R., L.K. Benjamin, and F. Messier. 1998. Prey switching and feeding habits of eastern coyotes in relation to snowshoe hare and white-tailed deer densities. Canadian Journal of Zoology. 76: 1885-1897. https://doi.org/10.1139/z98-135

Prange, S. and C. Rose. 2015. Diet of the Recovering Ohio Bobcat (Lynx rufus) with a Consideration of Two Subpopulations. The American Midland Naturalist. 173(2): 305-317. https://doi.org/10.1674/amid-173-02-305-317.1

R Core Team. 2013. A language and environment for statistical computing. R Foundation for Statistical Computing. Vienna, Austria.

Rockhill, A.P., C.S. DePerno and R.A. Powell. 2013. The Effect of Illumination and Time of Day on Movements of Bobcats (Lynx rufus). PLoS ONE. 8(7):1-7. https://doi.org/10.1371/journal.pone.0069213

U.S. Climate Data. 2015. Climate Zanesville-Ohio. Accessed on April 17, 2015 from http://www.usclimatedata.com/climate/zanesville/ohio/united-states/usoh2090/2014/1.

Weeks, J.L., G.M. Tori, and M.C. Shieldcastle, 1990. Coyotes (Canis latrans) in Ohio. Ohio Journal of Science. 90: 142-145.

Whitaker, J. 1996. National Audubon Society Field Guide to North American Mammals. Alfred A. Knopf, Inc. New York. 942 pp. 